\title{
RESPONDING TO CYBERBULlyING: THE CASE for FAMILY CONFERENCING
}

\section{Colette LANGos*}

\section{RICK SARRE**}

Cyberbullying is a form of anti-social conduct which is best understood as an online social relationship problem. Because of our growing understanding of the phenomenon, we can now see that any socio-legal response should envisage, therefore, a relationship solution. This article considers how one diversionary criminal justice process is particularly well suited to responding to incidents of cyberbullying where juveniles are involved yet which are deemed to be sufficiently serious to attract a potential criminal penalty. It explores, specifically, the option of family conferences (facilitated by youth justice co-ordinators) within the South Australian youth court framework. It concludes that both young cyberbullies and young victims of cyberbullying may benefit from alternatives to a retributive justice process, given that the primary focus of family conferencing is the repair of harm and the restoration of relationships.

\section{I 'Cyberbullying’ as a Phenomenon}

Over the past ten years researchers have examined the nature, scope and negative consequences associated with cyberbullying. ${ }^{1}$ With the exponential

\footnotetext{
${ }^{*}$ BA, LLB, GDLP, MComL, PhD; Lecturer in Law, Adelaide University.

** LLB, MA, SJD, JDhc; Professor of Law and Criminal Justice, University of South Australia. The authors are grateful for the assistance of Carolyn Doherty of the SA Family Conferencing Unit for her comments on an earlier draft.

${ }^{1}$ See, for example, Justin W Patchin and Sameer Hindujam 'Bullies move beyond the schoolyard: a preliminary look at cyberbullying' (2006) 4(2) Youth Violence and Juvenile Justice 148; Robert Slonje and Peter K Smith, 'Cyberbullying: Another Main Type of Bullying?' (2008) 49 Scandinavian Journal of Psychology 147; Barbara Spears et al, Research on Youth Exposure to, and Management of, Cyberbullying Incidents in Australia: Part A - Literature Review on the Estimated Prevalence of Cyberbullying involving Australian Minors (SPRC Report 9/2014) (Social Policy Research Centre, UNSW, 2014).
} 
growth of the knowledge base in this area, we have now moved into a mature phase of our understanding of the phenomenon.

\section{A Definition}

One aspect of cyberbullying which continues to provoke academic debate relates to its definition. There is, however, a growing consensus as to the key elements which constitute cyberbullying. ${ }^{2}$ These components are: intention (the conduct must be intended, as opposed to accidental); aggression (the conduct involves malice on the part of the aggressor); power imbalance (the conduct exerts power over the target); and repetition (the conduct occurs more than once). ${ }^{3}$ Generally, these criteria are considered to be the necessary elements differentiating bullying from mere aggression. ${ }^{4}$ One author captures these key features listed above by defining cyberbullying as 'intentional and aggressive online conduct intended to harm another who cannot easily defend him or herself'. 5 In a cyberbullying context, harm includes emotional harm, a term which embraces annoyance, humiliation, short-term grief, fear and anxiety, as well as more severe psychological harm, such as protracted psychological injury. ${ }^{6}$ Cyberbullying can be either direct (where the cyberbully directs the electronic communications to the victim only) or indirect (where the cyberbully

${ }^{2}$ Barbara Spears et al, above n 1, 6.

3 A single act can be considered 'repetition' each time the blog, website, video, email, photograph, or text message is accessed/viewed. See generally Colette Langos, 'Cyberbullying: The Challenge to Define' (2012) 15(6) Cyberpsychology, Behavior and Social Networking 285.

${ }^{4}$ Ibid; Peter K Smith et al, 'Cyberbullying: Its Nature and Impact on Secondary School Pupils' (2008) 49(4) Journal of Child Psychology and Psychiatry 376; Julian Dooley, Jacek Pyzalski and Donna Cross, 'Cyberbullying versus Face-to-Face Bullying: A Theoretical and Conceptual Review' (2009) 217(4) Zeitschrift für Psychologie (Journal of Psychology) 182. Interestingly, section 5 of the Enhancing Online Safety for Children Act 2015 (Cth) defines 'cyberbullying material targeted at an Australian child' in a more general manner which does not necessarily capture the key elements. The definition provides an objective test of the type of material a children's e-safety Commissioner may investigate and respond to, making no reference to repetition, power imbalance, intention or aggression per se. The Act does not create a criminal offence of cyberbullying. Rather, it establishes a comprehensive civil enforcement mechanism with one of the key functions being the administration of a complaints scheme in relation to cyberbullying material.

${ }^{5}$ Langos, above $\mathrm{n} 3$.

${ }^{6}$ In a legislative context, it is likely that 'harm' is limited to serious harm in order to minimise the criminalisation of conduct which does not necessarily warrant criminalisation. The definition provided in s 5 of the Enhancing Online Safety for Children Act 2015 does this by limiting 'cyberbullying material' to the kind of material which is likely to have the effect of 'seriously threatening, seriously intimidating, seriously harassing or seriously intimidating'. 
posts the communication directed at the victim to a publicly accessible area of cyberspace). ${ }^{7}$

\section{B Prevalence}

The primary research method employed to measure the prevalence of cyberbullying is the self-report survey. It is important to note that the definition of 'cyberbullying' used in a survey is likely to influence the outcome. For example, some studies have determined prevalence rates without including the elements of 'repetition' and 'power imbalance' in the definition. ${ }^{8}$ Such studies effectively measure a related construct — 'cyber aggression'. Cyber aggression includes instances of conflict in which there is no power imbalance in the relationship between sender and recipient of an electronic communication (fights between equals); often, for the definition of cyber aggression to be met, there is no requirement that the conduct occur numerous times. In cases where such broad definitions of cyberbullying are applied, the incidence rate is likely to be higher. ${ }^{9}$

Moreover, the way in which researchers frame the survey may also impact on the reported incidence rates. For example, a survey that provides a definition of cyberbullying and asks participants to self-identify whether or not they have experienced the conduct as defined is likely to lead to a finding of a lower incidence than a survey which asks respondents a series of questions based on the types of negative behaviours that constitute cyberbullying. The former method of survey design can lead to under-reporting, as respondents may not realise or admit that their experience constitutes the conduct defined in the survey. ${ }^{10}$

\footnotetext{
${ }^{7}$ Langos, above n 3; Susan Brenner and Megan Rehberg, "“Kiddie Crime"? The Utility of Criminal Law in Controlling Cyberbullying' (2009) 8(1) First Amendment Law Review 1, 13.

${ }^{8}$ For example, Jodie Lodge and Erica Frydenberg, 'Cyberbullying in Australian Schools: Profiles of Adolescent Coping and Insights for School Practitioners' (2007) 24(1) Australian Educational and Developmental Psychologist 45, 48; Michele J Fleming et al, 'Safety in Cyberspace: Adolescents' Safety and Exposure Online' (2006) 38(2) Youth and Society 135, 145. See generally Michele Ybarra et al, 'Defining and Measuring Cyberbullying within the Larger Context of Bullying Victimization' (2012) 51(1) Journal of Adolescent Health 53, 54.

${ }^{9}$ Ybarra et al, above $\mathrm{n} 8$.

${ }^{10}$ Ibid.
} 
The lack of a universally accepted definition of cyberbullying and the absence of standardised survey measurement techniques clearly make it difficult to determine accurately the rate at which cyberbullying is occurring in Australia today. ${ }^{11}$ Nevertheless there have been some credible attempts to measure the prevalence of the phenomenon. Recent findings indicate that the estimated number of young Australians aged 8-17 who have been victims of cyberbullying at any point in their lives is around $463000 .^{12}$ The report Research on Youth Exposure to, and Management of, Cyberbullying Incidents in Australia indicates that 'the best estimate of the prevalence for [sic] being cyberbullied "over a 12 months period" would be in the vicinity of 20 per cent of young Australians aged 8-17', with cyberbullying occurring most prominently within the age range of $10-15$ years. ${ }^{13}$ These findings are consistent with international findings, notwithstanding the variance in definition and measurement techniques applied. ${ }^{14}$

\section{Forms of Cyberbullying}

Cyberbullying can manifest itself in different forms and through different modes of communication, ${ }^{15}$ namely via email, SMS, websites, chatrooms, phone calls, picture/video clips and instant messaging, and encompasses a broad range of behaviours reflected in the identifiable manifestations of the conduct.

The various forms of cyberbullying are outlined below in Figure 1:

\footnotetext{
${ }^{11}$ It is imperative that a standardised definition of 'cyberbullying' is agreed upon to improve consistency in the measurement of the phenomenon, to enable cross country comparisons and to delineate cyberbullying from similar (arguably less harmful) constructs to enable effective policy intervention.

${ }^{12}$ Katz et al, Research on Youth Exposure to, and Management of, Cyberbullying Incidents in Australia: Synthesis Report (SPRC Report 16/2014) (Social Policy Research Centre, UNSW, 2014), 2. Note that the Report also indicates that the estimate could range between 100000 less to around 200000 more depending on the definition and measurement techniques used.

${ }^{13}$ Ibid 2.

${ }^{14}$ Spears et al, above $\mathrm{n} 1,1$.

${ }^{15}$ Brenner and Rehberg, above n 7; Colette Langos, 'Cyberbullying: The Shades of Harm' (2014) 22(1) Psychiatry, Psychology and Law 106, 107.
} 
Figure 1 Forms of Cyberbullying

Harassment involves repeatedly sending offensive messages to a target. ${ }^{16}$

Cyberstalking involves intense harassment and denigration that includes threats or creates significant fear in the victim. Harassment becomes cyberstalking when a victim fears for his or her personal safety. ${ }^{17}$

Denigration may involve making a derogatory comment about the target. There are several manifestations of this conduct. It can occur through the use of words or can involve the dissemination of a derogatory, sexual or non-sexual image. ${ }^{18}$

Happy slapping involves the filming of a physical assault on a victim and the subsequent distribution of the film to humiliate the victim publicly. ${ }^{19}$

Exclusion involves a victim being purposely excluded from entering online 'areas' such as a particular chatroom or discussion group by members of those online domains. ${ }^{20}$

Outing and trickery are tactics applied together. They involve a perpetrator manipulating the victim into disclosing information that the perpetrator then publicises in order to humiliate the victim. ${ }^{21}$

Impersonation or masquerading involves the perpetrator pretending to be the victim and sending an offensive message that appears to come from the victim. ${ }^{22}$

Indirect threat is a form of cyberbullying which is related to cyberstalking in that it involves an online communication of impending physical harm. Unlike cyberstalking, indirect threat involves a single threat of physical harm made indirectly in the public online domain. ${ }^{23}$

${ }^{16}$ Nancy Willard, Cyberbullying and Cyberthreats: Responding to the Challenge of Online Social Aggression, Threats and Distress (Research Press, 2007), 6; Sheri Bauman, 'Cyberbullying: A Virtual Menace' (Paper presented at the National Coalition against Bullying National Conference, Melbourne, Australia, November 2- 4, 2007), 2.

${ }^{17}$ Willard, above n 16, 10.

18 Colette Langos, Cyberbullying, Associated Harm and the Criminal Law ( $\mathrm{PhD}$ Thesis, University of South Australia, 2013), 55-60.

${ }^{19}$ Stephanie Chan et al, 'Understanding "Happy Slapping”" (2012) 14(1) International Journal of Police Science and Management 42, 44.

${ }^{20}$ Willard, above n 16, 9-10; Bauman, above n 16.

${ }^{21}$ Willard, above $\mathrm{n} 16,9$.

${ }^{22}$ Ibid 8 .

${ }^{23}$ Langos, above n 18, 64-6. 


\section{The Consequences of 'CYberbullying'}

Studies suggest that there are serious health and other consequences for victims of cyberbullying. It has been associated with a range of negative outcomes such as high levels of anxiety, ${ }^{24}$ suicidal ideation, ${ }^{25}$ depression ${ }^{26}$ and psychosomatic problems,${ }^{27}$ as well as behavioural problems such as aggressive behaviours and excessive consumption of alcohol. ${ }^{28}$ Such findings are similar to those that have emerged from traditional bullying research. ${ }^{29}$ Additionally, studies have shown that victims of cyberbullying experience more severe mental health effects than victims of traditional bullying. For example, research conducted in Australia and Switzerland in 2010, sampling 374 Swiss adolescents and 1320 Australian adolescents, reported that adolescent victims of cyberbullying experienced significantly higher levels of depressive symptoms than victims of traditional bullying; this was the case even when the researchers controlled for the perpetrator's involvement in 'traditional' bullying. ${ }^{30}$ This finding is supported by another Australian study which reported in 2012 that victims of cyberbullying experienced greater social difficulties and higher levels of anxiety and depression than victims of traditional bullying. ${ }^{31}$

${ }^{24}$ Jaana Juvonen and Elisheva Gross, 'Extending the School Grounds?-Bullying Experiences in Cyberspace' (2008) 78(9) Journal of School Health 496.

${ }^{25}$ Mitch van Geel, Paul Vedder and Jenny Tanilon, 'Relationship between Peer Victimization, Cyberbullying, and Suicide in Children and Adolescents: A Meta-Analysis' (2014) 168(5) JAMAPediatrics, 435; Sameer Hinduja and Justin W Patchin, 'Bullying, Cyberbullying and Suicide' (2010) 14(3) Archives of Suicide Research 206.

${ }^{26}$ Jing Wang, Tonja Nansel and Ronald Iannotti, 'Cyber and Traditional Bullying: Differential Association with Depression' (2011) 48(4) Journal of Adolescent Health 415.

${ }^{27}$ Andre Sourander et al, 'Psychosocial Risk Factors Associated with Cyberbullying among Adolescents: A Population-Based Study' (2010) 67(7) Archives of General Psychiatry 720.

${ }^{28}$ Ibid.

${ }^{29}$ Ken Rigby, 'Consequences of Bullying in Schools' (2003) 48(9) Canadian Journal of Psychiatry 583.

${ }^{30}$ Sonja Perren et al, 'Bullying in School and Cyberspace: Associations with Depressive Symptoms in Swiss and Australian Adolescents' (2010) 4(1) Child and Adolescent Psychiatry and Mental Health 28.

${ }^{31}$ Marilyn Campbell et al, 'Victims' Perceptions of Traditional and Cyberbullying, and the Psychological Correlates of their Victimisation' (2012) 17(3-4) Emotional and Behavioural Difficulties 389, 398. 


\section{FACtORS LIKELY TO EXACERBATE THE HARM EXPERIENCED IN RELATION TO CYBERBULLYING}

\section{A Virtual distance between the 'Cyber World' and the 'Real World'}

Cyberbullying is clearly distinguishable from traditional bullying because it is facilitated through information communication technologies (ICTs). The use of ICTs can foster in the bully the perception of being protected from the repercussions of the bullying actions. The presence of 'the screen' can act as a 'disconnect' (a divider) between cyber acts and the 'real life' consequences of those actions, which 'disconnect' can also contribute to a perpetrator's 'disinhibition'. 'Disinhibition' is understood as a lack of inhibition. ${ }^{32}$ It has been defined as the 'inability to control impulsive behaviours, thoughts, or feelings, and manifests online as people communicating in ways that they would not ordinarily do offline' ${ }^{33}$ Online, a perpetrator may feel emboldened as a result of disinhibition, because it takes 'less energy and fortitude to express hurtful comments using a keyboard or keypad than using one's voice'. ${ }^{34}$ A perpetrator, who is sheltered from the visual or aural response of their victim by the presence of the screen, is less likely to be affected by feelings of empathy. As Albert Bandura suggests, 'it is relatively easy to hurt others when their suffering is not visible and when causal actions are physically and temporally remote from their effects' ${ }^{35}$ In situations where a victim's suffering is seen or heard, vicariously aroused distress and self-censure serve as selfrestraining influences. ${ }^{36}$ The physical distance between a cyberbully and a victim, however, creates a context where malicious conduct can be ignored or trivialised and produces a power imbalance between perpetrator and victim.

\footnotetext{
${ }^{32}$ Jayne Gackenback and Heather von Stackelberg, 'Self Online: Personality and Demographic Implications' in Jayne Gackenback (ed), Psychology and the Internet: Intrapersonal, Interpersonal and Transpersonal Implications (2nd ed, 2011) 58, 58; Adam Joinson, 'Causes and Implications of Disinhibited Behavior on the Internet' in Jayne Gackenback (ed), Psychology and the Internet: Intrapersonal, Interpersonal and Transpersonal Implications (1998) 43.

${ }^{33}$ Gackenback and von Stackelberg, above n 32.

${ }^{34}$ Justin W Patchin and Sameer Hinduja, 'Bullies Move Beyond the Schoolyard: A Preliminary Look at Cyberbullying' (2006) 4(2) Youth Violence and Juvenile Justice 148, 154.

${ }^{35}$ Arnold Bandura, 'Social Cognitive Theory of Moral Thought and Action' in William M Kurtines and Jacob L Gewirtz (eds), Handbook of Moral Behavior and Development (Lawrence Erlbaum Associates, 1991) vol 1, 86.

${ }^{36}$ Ibid.
} 
The opportunity for the misuse of ICTs grows with the popularity and accessibility of such devices. Educating society to be 'responsible' digital citizens is critical to negating a perception that actions in cyberspace have few or no consequences, that cyberspace is detached from 'real' space.

\section{B Perceived Anonymity}

Research findings suggest that most perpetrators do not conceal their identity. ${ }^{37}$ However, some cyberbullies do hide behind a veil of anonymity. A perpetrator is able to create a pseudonym, to make up a provisional email address and to block a telephone number to conceal his or her identity. These technological possibilities make cyberbullying a particularly 'insidious form of bullying' ${ }^{38}$ Anonymity may exacerbate the power imbalance between the perpetrator and victim. A victim may experience fear and insecurity as a result of not knowing the identity of the perpetrator. ${ }^{39}$ A victim may feel frustrated and powerless. ${ }^{40}$

\section{Lack of Boundaries in Cyberspace}

Technology enables pervasive bullying. The home no longer provides refuge from the schoolyard bully or from the bully at the sports club. Victimisation is no longer limited to a time or place. ${ }^{41}$ A cyberbully is unrestricted by geographic location. For 'digital natives' (Generations $\mathrm{Y}$ and $\mathrm{Z}$ ) there appears a seamless transition between the worlds of the virtual and the physical. It therefore becomes exceedingly difficult for youths to separate themselves from the virtual world, this exposing them to online risks any time of the day or night. ${ }^{42}$

\footnotetext{
${ }^{37}$ Donna Cross et al, 'Australian Covert Bullying Prevalence Study' (Child Health Promotion Research Centre, Edith Cowan University, 2009).

${ }^{38}$ Sameer Hinduja and Justin W Patchin, Bullying Beyond the Schoolyard: Preventing and Responding to Cyberbullying (2009).

39 Annalaura Nocentini et al, 'Cyberbullying: Labels, Behaviours and Definition in Three European Countries' (2010) 20(2) Australian Journal of Guidance \& Counselling 129, 138.

${ }^{40}$ Heidi Vandebosch and Katrien Cleemput, 'Defining Cyberbullying: A Qualitative Research into Perceptions of Youngsters' (2008) 11(4) CyberPsychology \& Behaviour 499, 502.

${ }^{41}$ Nicole Bluett-Boyd et al, 'The Role of Emerging Communication Technologies in Experiences of Sexual Violence: A New Legal Frontier?' (Australian Institute of Family Studies No 23, 2013) 19; Helen McGrath, Young People and Technology: A Review of the Current Literature ( $2^{\text {nd }}$ ed) (2009) 28.

${ }^{42}$ Karen Brown, Margaret Jackson and Wanda Cassidy, 'Cyber-Bullying: Developing Policy to Direct Responses That Are Equitable and Effective in Addressing this Special Form of Bullying' (2006) 57 Canadian Journal of Educational Administration and Policy 1, 10.
} 


\section{Potentially Global Audience}

The nature of technology allows for this new breed of bullying to be particularly humiliating for a victim. In the case of indirect forms of cyberbullying, the public nature of the material has the potential to humiliate the victim publicly. The potentially infinite number of witnesses to the conduct may heighten a victim's feelings of powerlessness. Additionally, once material is posted to a public online forum, a victim is not able to control who saves and forwards the material thereafter. ${ }^{43}$ Moreover, the potential permanence of the publicly accessible material (material which has been posted to publicly accessible areas in cyberspace, such as YouTube, social media websites, other websites or blogs, or has been communicated via SMS or email with multiple recipients) may produce a power imbalance between a perpetrator and victim. The inability of a victim to remove the publicly accessible material from cyberspace gives the perpetrator the 'upper hand'.

These factors are unique to cyberbullying and are likely to intensify the impact experienced by those exposed to the conduct.

\section{Are All Forms of Cyberbullying Equally HARMFUL?}

Not all incidents of cyberbullying result in victims experiencing harm; there are many 'shades of harm' associated with cyberbullying. ${ }^{44}$ Some victims may experience negligible or merely trivial harm $^{45}$ and others may experience protracted psychological injury ${ }^{46}$ Empirical research specifically examining the harmfulness of particular forms of cyberbullying is scant. However, studies have been conducted in the United Kingdom and Sweden, ${ }^{47}$ and in three other European countries (Spain, Germany and Italy) ${ }^{48}$ which have indicated that visual modes of cyberbullying are the most serious (most harmful) forms of cyberbullying. A more recent study sampling 1092 Italian adolescents evaluated the severity of the impact of different modes of cyberbullying. It

\footnotetext{
${ }^{43}$ Bluett-Boyd et al, above n 41, 22.

${ }^{44}$ Langos, above $\mathrm{n} 15$.

${ }^{45}$ Michele Ybarra et al, 'Examining Characteristics and Associated Distress Related to Internet Harassment: Findings from the Second Youth Internet Safety Survey' (2006) 118(4) Pediatrics 1719.

${ }^{46}$ Langos, above n $18,117-26$.

${ }^{47}$ Robert Slonje and Peter K Smith, 'Cyberbullying: Another Main Type of Bullying?' (2008) 49(2) Scandinavian Journal of Psychology 147.

48 Annalaura Nocentini et al, 'Cyberbullying: Labels, Behaviours and Definition in Three European Countries' (2010) 20(2) Australian Journal of Guidance \& Counselling 129.
} 
moved beyond the perception studies (above) to look at how cyberbullying was experienced by participants in the study. ${ }^{49}$ Findings indicated that the most damaging modes of cyberbullying for both males and females are the visual modes including the communication of phone pictures/photos/videos of intimate scenes ('denigration by way of a sexual or intimate image'), and phone pictures/photos/videos of violent scenes ('happy slapping' and 'denigration by images/video recordings'). ${ }^{50}$

A 2014 analysis examining the potential harm associated with various forms of cyberbullying, based on initial empirical research and a crime seriousness framework ${ }^{51}$ originally applied to traditional crimes, provides valuable theoretical insight into the associated harms of all forms of cyberbullying. ${ }^{52}$ Forms of bullying were ranked from most to least serious, with 'happy slapping', 'denigration' by way of a sexual or intimate image, and 'cyberstalking' assessed as being the most serious. ${ }^{53}$

Other research is providing a better understanding of the phenomenon of cyberbullying from a criminological perspective. ${ }^{54}$ The research indicates that the majority of perpetrators (cyberbullies) are known to the victim, and that most do not conceal their identity. ${ }^{55}$ This suggests that instances of cyberbullying typically arise within a particular social context and that the behaviour is indicative of a social relationship problem. ${ }^{56}$

The evidence base for effective interventions in cyberbullying is still in its infancy in relation to cyberbullying. ${ }^{57}$ Most instances of cyberbullying between young people are managed, without police intervention, through the use of disciplinary measures (such as those available in schools) and through schoolbased or workplace conflict resolution mechanisms. However, serious instances

49 Ersilia Menesini et al, 'The Measurement of Cyberbullying: Dimensional Structure and Relative Item Severity and Discrimination' (2011) 14(5) Cyberpsychology, Behaviour and Social Networking 267.

${ }^{50}$ Ibid.

${ }^{51}$ A theoretical (non-empirical) method of assessing the seriousness of particular criminal behaviours. See, for example, Andrew von Hirsch and Nils Jareborg, 'Gauging Criminal Harm: A Living Standard Analysis' (1991) 11(1) Oxford Journal of Legal Studies 1.

${ }^{52}$ Langos, above $\mathrm{n} 15$.

${ }^{53}$ Ibid.

${ }^{54}$ Wendy M Craig and Debra J Pepler, 'Understanding Bullying: From Research to Practice' (2007) 48(2) Canadian Psychology 86, 88.

${ }^{55}$ For example, Slonje and Smith, above n 47; Cross et al, Australian Covert Bullying Prevalence Study (Child Health Promotion Research Centre, Edith Cowan University, 2009).

${ }^{56}$ Katz et al, above n 12, 10.

${ }^{57}$ Spears et al, above $\mathrm{n} 1,62$. 
of cyberbullying may require a police response. In the following sections, we briefly consider various criminal law responses under the Australian criminal law framework, with a particular focus on South Australian law.

\section{Responses to Cyberbullying: Criminal LaW OPTIONS}

Cyberbullying per se is not defined by law in Australia, nor is it prosecuted as a distinct crime. Indeed, there is no specific law criminalising the phenomenon. A host of state and federal laws are, however, capable of regulating instances of cyberbullying where the conduct in question falls within the scope of existing offence definitions. ${ }^{58}$ Serious instances of the conduct can be prosecuted in most cases, but this is only possible through piecemeal processes, not a comprehensive approach. ${ }^{59}$ Notably, South Australia has recently enacted 'filming' legislation which widens the scope of conduct that amounts to cyberbullying regulated by South Australian criminal law. ${ }^{60}$ Specifically, the legislation expands the types of proscribed conduct to include a victim being filmed without his or her consent, where that film is then distributed via ICTs. This legislation now captures the filming and distribution of any conduct deemed to be 'humiliating or degrading' and in this way comprehensively regulates one of the most serious forms of cyberbullying — 'happy slapping'. ${ }^{61}$ South Australia is the first jurisdiction in Australia to enact such legislation. ${ }^{62}$

\footnotetext{
${ }^{58}$ For an overview see, for example, Sally Kift, Marilyn Campbell and Desmond A Butler, 'Cyberbullying in Social Networking Sites and Blogs: Legal Issues for Young People and Schools' (2010) 20(2) Journal of Law, Information and Science 60. For a detailed South Australian perspective see Colette Langos, 'Regulating Cyberbullying: A South Australian Perspective' (2014) 16(1) Flinders Law Journal 73. Because the Commonwealth has jurisdiction over 'postal, telephonic and other like services' as stipulated in s 51(v) of the Constitution, the federal Parliament was able to enact the Crimes Legislation Amendment (Telecommunications Offences and Other Measures) Act 2005 (Cth) which introduced a range of new federal telecommunications offences which are contained in a Schedule to the Criminal Code Act 1995 (Cth) - the Criminal Code.

${ }^{59}$ Langos, above $\mathrm{n} 58$. States should be encouraged to conduct regular reviews of their existing criminal laws to ensure serious instances of cyberbullying are regulated.

${ }^{60}$ Summary Offences (Filming Offences) Amendment Act 2013 (SA). The Act amends Part 5A of the Summary Offences Act 1953 (SA).

${ }^{61}$ What is considered 'humiliating and degrading' is to be determined on a case by case basis, using an objective standard. See, Summary Offenders Act 1953 (SA) s 26D.

${ }^{62}$ Prior to the introduction of the 'filming offences', existing laws could regulate aspects of 'happy slapping' by virtue of, for example, state legislation governing 'assault' (potentially capturing the assault component of 'happy slapping'), 'indecent filming' legislation (potentially
} 


\section{Responses to Cyberbullying: Justice System OPTIONS}

We turn now to consider how the South Australian juvenile justice system could best respond to and accommodate young cyberbullies who are guilty of engaging in serious instances of cyberbullying such as 'happy slapping'.

Like all other jurisdictions in Australia, the South Australian juvenile justice system affords special protections to youths under the age of 18, given their welfare needs. The Young Offenders Act 1993 (SA) applies to youths above the age of 10 years but under the age of 18 years. ${ }^{63}$ In South Australia, a person who is under the age of 10 cannot be charged with a criminal offence. ${ }^{64}$ The common law doctrine of doli incapax applies to youths aged between 10-14 years in all Australian jurisdictions. ${ }^{65}$ However, once a youth is aged between 15 and 17 years, the youth is taken to have attained the developmental maturity to be held fully responsible for his or her actions under the criminal law.

The underlying principles of the Young Offenders Act emphasise restitution to victims, the strengthening of relationships (particularly family relationships) and the avoidance of disruption to a juvenile offender's employment or the impairment of the juvenile's sense of racial, ethnic or cultural identity. ${ }^{66}$

Under the Young Offenders Act, a tiered system of pre-court diversionary processes was established to deal with all offences to which that Act applies. These offences can include major indictable offences but are in practice, for the most part, 'minor' offences ${ }^{67}$ Depending on the gravity of the 'minor' offence, a youth may be given one of what are referred to officially as 'informal' or

\footnotetext{
capturing filming of an 'indecent' nature) and federal legislation 'misuse of telecommunications' provisions.

${ }^{63}$ Young Offenders Act 1993 (SA) s 4.

${ }^{64}$ Ibid s 5. This minimum age of criminal responsibility is mirrored in all other Australian jurisdictions. See, Criminal Code Act Compilation Act 1913 (WA), s 29; Children, Youth and Families Act 2005 (Vic), s 344; Criminal Code Act 1924 (Tas), s 18(1); Criminal Code Act 1899 (Qld), s 29(1); Criminal Code Act (NT), s 38(1); Children (Criminal Proceedings) Act 1987 (NSW), s5; Criminal Code 2002 (ACT), s 25; Crimes Act 1914 (Cth), s 4M, Criminal Code Act 1995 (Cth), s 7.1.

${ }^{65}$ Doli incapax is a rebuttable legal presumption that a youth 10-14 years of age is incapable of crime under either statute or the common law because of a lack of understanding of the differences between right and wrong, and a consequential lack of mens rea. See Gregor Urbas, 'The Age of Criminal Responsibility' (2000) 181 Trends and Issues in Crime and Criminal Justice (Australian Institute of Criminology) 3-4.

${ }^{66}$ Young Offenders Act 1993 (SA) s 3(3)(a)-(e).

${ }^{67}$ Ibid s 4.
} 
'formal' cautions. ${ }^{68}$ An 'informal' caution is not recorded for the purposes of a criminal record and cannot be used without the youth's consent in any judicial proceedings. ${ }^{69}$ It may be administered for 'trivial' offences where a police officer is of the opinion that the matter does not warrant any formal action. Informal cautioning therefore involves an element of discretion by the attending police officer. ${ }^{70} \mathrm{~A}$ 'formal' caution normally involves the youth entering into an undertaking, which may involve an apology to the victim and/or community service. ${ }^{71}$ It must be put in writing and acknowledged by the youth (also in writing) and, where practicable, must be administered in the presence of the youth's parent or guardian. ${ }^{72}$ Importantly, the guardians of the youth must be given the opportunity to make representations with respect to the matter. ${ }^{73}$ The most recent available data indicate that, of the 6292 apprehensions of juveniles lodged by police in South Australia in 2007, 33.2 per cent resulted in a formal caution. ${ }^{74}$ Most matters dealt with by way of caution are summary offences and less serious indictable offences. An effective cautioning system has been described as being crucial to the successful functioning of South Australia's diversionary system. ${ }^{75}$

A refusal by the youth offender to enter into an undertaking by way of a 'formal' caution (for example, an undertaking to apologise to the victim) may result in a referral to what is known as 'family conferencing, ${ }^{76}$ a system adopted in 1994 in South Australia (and elsewhere around Australia) ${ }^{77}$ based upon a comparable New Zealand model. Offences considered too serious to be appropriately dealt with by way of cautioning can be referred to family conferencing for resolution. Youths who have a history of receiving cautions

\footnotetext{
${ }^{68}$ Ibid ss 6-8.

${ }^{69}$ Ibid s 6.

${ }^{70}$ Ibid s 6(1).

${ }^{71}$ Ibid s 8(1).

${ }^{72}$ Ibid s $8(2)$.

${ }^{73}$ Ibid s 8(3).

${ }^{74}$ Office of Crime Statistics and Research, 'Crime and Justice in South Australia 2007 Juvenile Justice' (Research paper No 44 (2), South Australian Attorney General's Department, 2010) 4.

75 Joy Wundersitz, 'Family Conferencing in South Australia and Juvenile Justice Reform' in Christine Alder and Joy Wundersitz (eds), Family Conferencing and Juvenile Justice: The Way Forward or Misplaced Optimism? (Australian Institute of Criminology, 1994) 93.

${ }^{76}$ Young Offenders Act 1993 (SA) s 8(7).

77 Jacqueline Joudo-Larsen, Restorative Justice in the Australian Criminal Justice System (Australian Institute of Criminology Reports, Research and Public Policy Series 127, 2014) 6.
} 
for offending behaviour but who continue that behaviour may be referred as appropriate 'conference' candidates. ${ }^{78}$

Family conferencing is a mechanism designed to divert young people away from adversarial criminal justice processes towards the restoration of relationships. ${ }^{79}$ Its practice in South Australia is widespread and has the confidence of the profession and judiciary. A family conference is convened by a Youth Justice Coordinator (YJC), whose role is central to the process. ${ }^{80}$ The YJC acts as the mediator between parties. As Marni Harding and Stewart Potter state:

it is the role of the Youth Justice Coordinator to attempt to negotiate a decision which all participants consider a fair, reasonable and achievable outcome, and is acceptable to both the young person and police officer present, in addition to achieving all of the objectives of the Young Offenders Act, $1993 .^{81}$

Other participants of a family conference include the offender (who is entitled to legal advice for the conference), ${ }^{82}$ his or her support person(s), the victim and his or her support person(s) (although it is not compulsory that the victim attend), a police officer and any other party who has had a close association with the offender and may (in the opinion of the authorised officer) be able to participate usefully in the family conference. ${ }^{83}$ A personal representative or representative from the South Australian Victim Support Service ${ }^{84}$ may attend on the victim's behalf. ${ }^{85}$

Conference discussions are based on the offending behaviour and the impact on the victim, and are aimed at achieving an outcome, which may involve

${ }^{78}$ Young Offenders Act 1993 (SA) s 7(1)(b).

${ }^{79}$ Rick Sarre, 'Restorative Justice: Translating the Theory into Practice' (1999) 1 Notre Dame Australia Law Review 11.

${ }^{80}$ Young Offenders Act 1993 (SA) ss 10, 11.

${ }^{81}$ Marni Harding and Stewart Potter, 'Reaching Meaningful Outcomes in Family Conferencing' (Paper presented at the Juvenile Justice: From Lessons of the Past to a Road for the Future, Sydney, Australia, 1-2 December 2003) 3.

${ }^{82}$ Young Offenders Act 1993 (SA) s 11(4).

${ }^{83}$ Ibid s 10.

84 'Victim Support Service' is a South Australian non-government support service where victims of crime can receive free and confidential help. The organisation works closely with multiple organisations to assist victims of crime <http://www.victimsa.org/>.

${ }^{85}$ Young Offenders Act 1993 (SA) s 10; Youth Court of South Australia Courts Administration Authority, Family Conferences <http://www.courts.sa.gov.au/OurCourts/YouthCourt/Pages/ Family-Conferences.aspx>. 
sanctions imposed on the offender or may involve the offender entering into an undertaking to carry out a form of reparation. ${ }^{86}$ Sanctions and reparations may include the issuing of a formal caution against further offending ${ }^{87}$ requiring the offender to pay some form of monetary compensation to the victim; ${ }^{88}$ requiring the offender to commit to community service (not exceeding 300 hours) $;{ }^{89}$ requiring the offender to apologise to the victim; ${ }^{90}$ or anything else that may be appropriate in the circumstances. ${ }^{91}$ The Young Offenders Act provides sufficient scope to "customise outcomes of family conferences, in order to meet the needs of, and therefore attempt to provide tangible meaning for, all parties involved'. ${ }^{2}$

To that end family conferencing aligns with restorative justice principles. These principles focus upon "problem-solving, dialogue and restitution (where possible), mutuality, the repair of social injury and the possibilities of repentance and forgiveness'. ${ }^{93}$ The conference aims to 'make young people accountable for their offences by encouraging them to take responsibility for their actions ${ }^{94}$ in a setting which cultivates 'an understanding of the other' ${ }^{95}$ Where a traditional justice model focuses on attributing blame and delivering 'just deserts' (offender-focused justice model), a restorative process focuses on problem-solving dialogues, mutuality, repairing social injury and fostering the possibility of forgiveness (a victim-focused justice model) ${ }^{96}$ Thus, a key focus of this response is on healing the harm caused and equalising the balance of power between a perpetrator and a victim.

Legal and educational professionals in South Australia have long been confident that bullying can be dealt with outside of the formal court process. Founded in 1997, the Centre for Restorative Justice in South Australia has been

\footnotetext{
${ }^{86}$ Kathleen Daly and Hennessey Hayes, 'Restorative Justice and Conferencing in Australia' (2001) 186 Trends and Issues in Crime and Criminal Justice 1, 2.

${ }^{87}$ Young Offenders Act 1993 (SA) s 12(1)(a).

${ }^{88}$ Ibid s 12(1)(b).

${ }^{89}$ Ibid s 12(1)(c).

${ }^{90}$ Ibid s 12(1)(d).

91 Ibid.

${ }^{92}$ Harding and Potter, above $\mathrm{n} 81$.

${ }^{93}$ Sarre, above n 79, 98.

${ }^{94}$ Christine Alder and Joy Wundersitz, 'New Directions in Juvenile Justice Reform in Australia' in Christine Alder and Joy Wundersitz (eds), Family Conferencing and Juvenile Justice: The Way Forward or Misplaced Optimism? (Australian Institute of Criminology, 1994), 7.

95 Alex Newbury, 'Youth Crime: Whose Responsibility?' (2008) 35(1) Journal of Law and Society 131, 137.

${ }^{96}$ Sarre, above n 79.
} 
proactively encouraging South Australian schools to adopt restorative justice practices within their 'behaviour development' school policies. ${ }^{97}$ Research examining the effectiveness of restorative justice implementation in eleven South Australian schools (including government, independent and Catholic schools) reported that, after the introduction of restorative practices, every school participating in the study found that student cooperation with behaviour management processes to be high or very high. ${ }^{98}$ Findings suggest that the implementation of restorative practices are effective in fostering student cooperation regarding behaviour management procedures. Additionally, all schools reported a positive change in the school climate since the introduction of the new practices; eight of the eleven schools reported that peer relations had improved to a high or very high level, and ten schools reported improvement of the teacher/student relationship as a result of the implementation of restorative justice practices. ${ }^{99}$ A South Australian school that has recently utilised restorative practices to deal with behaviour management, including bullying, has reported significant success, with suspensions dropping to almost one third of what they were in $2003 .^{100}$

But how far can family conferencing reach? In the following paragraphs we consider whether a family conference can be an appropriate and effective forum to respond to criminal conduct amounting to cyberbullying.

\section{Is Conferencing an Appropriate Response to Cyberbullying BetWeen JuVEniLes?}

Young people often test moral boundaries and over-step the boundaries of ethical norms. Criminal conviction and punishment have serious long-term implications for the offender. Yet youthful actions are often the result of

\footnotetext{
97 Centre for Restorative Justice, Annual Reports 2009-2010 <http://www.restorative justice.com.au/about_annual_reports.php>.

${ }^{98}$ Centre for Restorative Justice, 'Effectiveness of Restorative Justice Implementation in South Australian Schools' (2009), 6. Prior to the introduction of restorative justice practices only two schools reported student co-operation with behaviour management processes to be high or very high.

${ }^{99}$ Ibid 7-8.

100 Amy Noonan, 'Campbelltown Primary School's Justice for All Sees Grades Rise and Behaviour Improve' The Advertiser (online), 28 March $2011<\mathrm{http} / / / \mathrm{www}$.adelaidenow.com. $\mathrm{au} /$ campbelltown-primary-schools-justice-for-all-sees-grades-rise-and-behaviour-improve/ story-e6frea6u-1226029020710>.
} 
impulsive decisions motivated by the desire for social reward, revenge, retaliation, ${ }^{101}$ power within a peer group ${ }^{102}$ or 'entertainment'. ${ }^{103}$

Cyberbullying between juveniles which warrants police involvement (instances which cannot be resolved via school or workplace conflict resolution strategies, and those which breach a criminal law) will be dealt with, most of the time, by way of a caution, as described above. Where the perpetrator is a repeat young offender or where the conduct involves serious criminal conduct, the matter is likely to proceed to court or to a family conference. Indeed, the experience of the Family Conference Unit in South Australia is that there have been significant referrals to the Unit for young people who have engaged in 'sexting' activities. Sexting involves 'emails, text messages and other forms of electronic communication that contain sexual material, such as suggestive or provocative text, or images that are nude, nearly nude or sexually explicit'. ${ }^{104}$ Where the behaviours are of a pornographic nature, it is more likely than not that the young person will be referred to the Mary Street Adolescent Sexual Abuse Prevention Program. ${ }^{105}$

From the perspective of victims of cyberbullying, a family conference forum provides victims with:

- an opportunity to convey to offenders how cyberbullying has impacted them;

- an opportunity to get some answers as to why they were victimised;

${ }^{101}$ Chan et al, above n 19. Consider, for example, the instance where one person, formerly in a relationship with another person, seeks revenge by posting naked images (taken with consent) of the other person on the internet without the subject's consent. This behaviour type is also known as 'revenge porn'.

102 Ibid.

${ }^{103}$ Cyberbullying is reported to be considered to be 'thrilling' or 'funny': Peter K Smith et al, above n 4. See, more generally, Barbara Spears et al, Research on Youth Exposure to, and Management of, Cyberbullying Incidents in Australia: Part C-An Evidence-Based Assessment of Deterrents to Youth Cyberbullying - Appendix A (SPRC Report 12/2014) (Social Policy Research Centre, UNSW, 2014) 10.

104 Michael Salter, Thomas Cofts and Murray Lee, 'Beyond Criminalisation and Responsibilisation: 'Sexting, Gender and Young People' (2013) 24(3) Current Issues in Criminal Justice 301, 301. For a recent article exploring the criminal laws which regulate sexting in South Australia see Colette Langos, 'Sexting: Time for Some Changes to the Law?' (2014) 36(10) Bulletin 18-20.

105 Mary Street Sexual Abuse Prevention Program (2014), <http://sacommunity.org/ org/202590-Mary_Street_-_Adolescent_Sexual_Abuse_Prevention_Program $\rangle$. 
- an opportunity to hear the offenders apologise;

- an environment which fosters voluntary forgiveness by the victims;

- a forum where certain undertakings are entered into by the offenders.

From the perspective of a cyberbully, the forum provides an offender with:

- an opportunity to be diverted away from the Youth Court;

- an opportunity to avoid a criminal prosecution and potential for a conviction;

- an opportunity to explain the circumstances of the offence;

- some insight regarding how cyberbullying has impacted on the victim;

- an opportunity for the offender to experience empathy for the victim;

- an opportunity for him or her to apologise to the victim;

- an opportunity to commit to specific undertakings.

It is timely to review the likely sorts of undertakings that are available to the conferencing team coordinator. Where a film or image has been posted to the Internet and the film or image has not yet been removed, removal is likely to be a condition of the undertaking. ${ }^{106}$ Where an assault by 'happy slapping' is of a sexual nature, a condition of the undertaking may require the offender to commit to attend counselling at an appropriate agency (irrespective of whether the victim attends the conference). Additionally, a potentially appropriate condition of the undertaking may be to involve the offender in writing an essay, or preparing a pamphlet, poster or notice on the harmful nature of the offence to raise awareness of this harm among the offender's peers, and to assist in discouraging others from engaging in this conduct. In our view, each of these requirements provides a victim with a sense of validation and demonstrates that offenders are to be held accountable for their actions.

\footnotetext{
${ }^{106}$ It may also be a requirement that the IT device that was used to make and send the image be surrendered to police. This will not necessarily permanently delete the film or image from cyberspace as the image could have been saved and forwarded by anyone who had gained access to it.
} 
If one appreciates that suboptimal relationships are at the core of cyberbullying (as is the case in relation to traditional bullying), then one can speculate that the most enduring solutions, interventions or responses to cyberbullying will emphasise the improvement of young peoples' online relationships rather than the punishment of young people through the court process. It is opportune, then, that the structure of the juvenile justice system allows for the diversion of serious instances of cyberbullying to family conferencing, and we would argue that such diversionary practices should be applauded.

Although evidence is mixed concerning recidivism rates after conferencing, ${ }^{107}$ one should note that recidivism rates are not the only indicators of the efficacy of restorative justice models. A victim's satisfaction with a restorative justice process and the outcome achieved by that process are important indicators of whether or not the process is achieving its goal of restoring relationships, providing restitution and aiding the healing process. ${ }^{108}$ The most recent data suggest that approximately one third of victims are present at family conferences. ${ }^{109}$ The low rate of attendance by victims may be attributable to several factors, including fear of meeting the offender, feeling the crime to be trivial, or wanting the offender to face a harsher punishment. ${ }^{110}$ However, studies consistently report that victims who do participate in family conferencing experience high levels of victim satisfaction in regard to the process and the outcome. ${ }^{111}$ For example, findings from the Reintegrative Shaming Experiments project in Canberra (which examined the effects of standard court processing compared with the effects of a diversionary conference) indicate that victims who attend conferences benefit from their attendance. ${ }^{12}$ Victims of juvenile personal property offences reported significantly higher feelings of sympathy for the offender (and the offender's supporters) after the conference, as well as lower levels of anger. ${ }^{113}$ Two-thirds of victims reported that the conference gave them a sense of closure and

\footnotetext{
${ }^{107}$ Joudo-Larsen, above n 77, 23-6.

${ }^{108}$ Kathleen Daly, Restorative Justice and Conferencing, in Adam Graycar and Peter Grabosky, Peter (eds), The Cambridge Handbook of Australian Criminology (Cambridge University Press, 2002) 294-331.

${ }^{109}$ Office of Crime Statistics and Research, above n 74, 6.

110 Mike Neimeyer and David Shichor, 'Preliminary Study of a Large Victim/Offender Reconciliation Program' (1996) 60(3) Federal Probation 30, 32.

111 Joudo-Larsen, above n 77, $26-7$.

112 Heather Strang et al, Experiments in Restorative Policing: Final report on the Canberra Reintegrative Shaming Experiments (RISE) (Regulatory Institutions Network, College of Asia and the Pacific and Australian National University, 2011), Chapter 7.

${ }^{113}$ Ibid.
} 
reported that their sense of security had been restored. ${ }^{114}$ Victims of youth violence also reported feeling more sympathy towards the offender and supporters after the conference, as well as lower levels of anger and fear of their offender. ${ }^{115}$ Another important source of satisfaction for victims of both property offences and youth violence was the significantly higher level of apologies forthcoming from offenders than occurred in court. ${ }^{116} \mathrm{~A}$ study evaluating the youth justice conferencing scheme in New South Wales reported that 79 per cent of victims and 90 per cent of offenders were satisfied with how their cases had been dealt with. ${ }^{117}$ In Queensland, a comparable study revealed that 98 per cent of offenders and 97 per cent of victims felt that conferences were fair, and 99 per cent of offenders and 98 per cent of victims were satisfied with the overall outcome of the process. ${ }^{118}$

In light of the above, victims of cyberbullying should be encouraged to attend family conferences wherever possible. Youth courts and police should be encouraged to continue to refer young people to conferencing where it is not inappropriate. Positive results achieved by way of family conferencing should be publicised as widely as possible. ${ }^{119}$

\section{CONCLUSION}

A relationship problem that leads to crime is likely to require a relationship solution, rather than criminal punishment. The application of restorative justice principles through family conferencing in the juvenile justice system provides a workable mechanism for repairing harm and restoring relationships even in instances of serious cyberbullying. ${ }^{120}$ These principles can facilitate a healing

\footnotetext{
${ }^{114}$ Ibid.

115 Ibid.

116 Ibid.

${ }^{117}$ Lily Trimboli, An Evaluation of the NSW Youth Justice Conferencing Scheme (New South Wales Bureau of Crime Statistics and Research, 2000).

${ }^{118}$ Hennessey Hayes, Tim Prenzler and Richard Wortley, Making Amends: Final Evaluation of Queensland Community Conferencing Pilot, Queensland Department of Justice, Juvenile Justice Branch (1998).

${ }^{119}$ Rick Sarre, "We Get the Crime We Deserve: Exploring the Disconnect in "Law and Order" Politics' (2011) 18 James Cook University Law Review 144, 159.

120 There is a growing evidence base indicating that restorative practices, which focus on repairing harm and restoring relationships, are an effective intervention in relation to traditional (face to face) bullying as well. See, for example, Eliza Ahmed and John Braithwaite, 'Forgiveness, Shaming, Shame and Bullying' (2005) 38(3) The Australian and New Zealand Journal of Criminology 298; Centre for Restorative Justice, Annual Reports: 2009-2010 <http://www.restorativejustice.com.au/about_annual_reports.php>; Debra J Pepler, 'Bullying
} 
process whereby victims have the opportunity to explain the impact of the crime and learn something of the reasons for their victimisation. Conferencing provides cyberbullies with a forum that brings home to them the consequences of their actions in a more personal manner than a court process. Family conferencing thus can be viewed as an educative process which steers young people away from anti-social behaviours without the stigma of an appearance in juvenile court, nor a criminal record. It may even provide an opportunity for the cyberbully to mature emotionally as a result of the incident.

The authors posit that law-makers should be enjoined to embrace family conferencing as the preferred option in serious instances of cyberbullying where young people are involved. To borrow a phrase from Elliott Currie, 'we need to embrace interventions that align with our best values'. ${ }^{121}$ It is now up to policy-makers to make that happen.

Interventions: A Binocular Perspective' (2006) 15(1) Journal of the Canadian Academy of Child and Adolescent Psychiatry 16, 19; Marie Hutchinson, 'Restorative Approaches to Workplace Bullying' (2009) 32 (1-2) Contemporary Nurse 147.

${ }^{121}$ Elliott Currie, 'Consciousness, Solidarity and Hope as Prevention and Rehabilitation' (2013)

2(2) International Journal for Crime, Justice and Social Democracy 3, 10. 